\title{
End-stage Renal Disease Associated with Familial Mediterranean Fever
}

\author{
Nozomi Tomiyama, Saori Oshiro, Yasushi Higashiuesato, Masanobu Yamazato, Atushi Sakima, Takeshi Tana, \\ Masahiko Tozawa, Hiromi Muratani, Kunitoshi IseKI* and Shuichi Takishita
}

\begin{abstract}
A 39-year-old man had been suffering from periodic fever since childhood. He was started on hemodialysis due to secondary amyloidosis on December 2000. The patient was believed to have Familial Mediterranean fever (FMF) because of recurrent fever with peritonitis, arthritis and inflammatory changes and secondary amyloidosis in his kidneys, heart and colon. No other family member had recurrent fever. IL-6, TNF, and dopamine $\beta$-hydroxylase were not increased in the febril phase. The patient was homozygous for the M694I mutation. We report the first Japanese case of FMF associated with amyloidosis and confirmed by a gene mutation.

(Internal Medicine 41: 221-224, 2002)
\end{abstract}

Key words: periodic fever, amyloidosis, kidney, dialysis, MEFV gene, colchicine

\section{Introduction}

Familial Mediterranean fever (FMF) is an autosomal recessive disease, characterized by recurrent attacks of fever and peritonitis, pleuritis, arthritis, or erysipelas-like skin disease (1).

The disease is restricted to persons of Mediterranean descent especially sephardic Jews, Armenians, Turks, and Arabs. It is very rare in Japan. In 1997, the international and the French Familial Mediterranean fever consortia independently cloned the gene responsible for FMF, found on the short arm of chromosome 16 (MEFV) $(2,3)$. The gene responsible for FMF spans 10 exons, and encodes a 781 amino acid protein. To date, 26 mutations have been found in MEFV (4). Most mutations are missense mutations that result in the substitution of a single amino acid (1). In Japan, only 15 cases have been reported (5, 6). We report the first Japanese case of FMF associated with amyloidosis and diagnosed by the existence of the FMF gene.
Case Report

A 39-year-old man had been suffering from periodic fever of unknown origin accompanied with arthritis, abdominal pain and erythema nodosum-like skin lesions since he was 3 years old. He was diagnosed with rheumatic fever in infancy. He entered a hospital for examination of renal failure (serum creatinin level was $2.1 \mathrm{mg} / \mathrm{dl}$ ) and periodic fever with abdominal pain in 1998 . Spike fever of more than $38^{\circ} \mathrm{C}$ appeared and the laboratory studies showed an accelerated erythrocyte sedimentation rate, leukocytosis with neutrophilia, and increased levels of C-reactive protein. He was diagnosed with secondary amyloidosis by kidney and colon biopsy. Crohn's disease was diagnosed as a basal disease and treated by oral prednisolone and mesalazine. Thereafter, he had frequent febrile attacks once or twice a month lasting from 1 to 3 days accompanied by inflammatory findings, abdominal pain and arthritis. On October 29, 2000, he was admitted to hospital because of fever and pain. At the time of admission to the department of internal medicine of our hospital on October 31 , he had a low grade fever and severe pain due to polyarthritis.

The laboratory findings at that time are summarized in Table 1. The thyroid was swollen and the TSH level was elevated but thyroid hormones were within normal range. Chest X-ray films showed a small amount of fluid in the thoracic cavity and abdominal echocardiography and computed tomography showed slight accumulation of ascites, mild splenomegaly and atrophy of the bilateral kidneys (about $8 \mathrm{~cm}$ in size). X-ray films of extremities did not show joint deformity or other findings of rheumatoid arthritis. Cardiac ultrasonic examination showed marked cardiac hypertrophy with sparkling signs and slight pericardial effusion. Cultures for bacteria in the urine and blood and cultures for tuberculosis in the sputum and bone marrow were negative. Bone marrow examination and muscle biopsy did not show apparent abnormalities. An increased dose of prednisolone (20 mg/day) and antibiotics (Sulperazone) were not effective but fever and polyarthritis gradually disappeared in two weeks and the accelerated erythrocyte sedimentation rate, leukocytosis, and increased levels of C-reactive protein were

From the Third Department of Internal Medicine and *Dialysis Unit, University of The Ryukyus, Okinawa

Received for publication July 18, 2001; Accepted for publication October 25, 2001

Reprint requests should be addressed to Dr. Nozomi Tomiyama, the Third Department of Internal Medicine, University of The Ryukyus, 207 Uehara, Nishihara, Okinawa 903-0215 
Table 1. Laboratory Findings on Admission

\begin{tabular}{|c|c|c|c|c|c|}
\hline \multirow{2}{*}{\multicolumn{2}{|c|}{ [Peripheral blood] }} & \multicolumn{4}{|c|}{ [Serological test] } \\
\hline & & CRP & $2.06 \mathrm{mg} / \mathrm{dl}$ & UA & $12.7 \mathrm{mg} / \mathrm{dl}$ \\
\hline WBC & $28,700 / \mu \mathrm{l}$ & RA test & $(+)$ & $\mathrm{Na}$ & $140 \mathrm{mEq} / \mathrm{l}$ \\
\hline Seg+Stab & $93.0 \%$ & RA IgG & $(-)$ & $\mathrm{K}$ & $4.2 \mathrm{mEq} / \mathrm{l}$ \\
\hline Ly & $3.0 \%$ & LE test & $(-)$ & $\mathrm{Cl}$ & $102 \mathrm{mEq} / \mathrm{l}$ \\
\hline Mo & $2.0 \%$ & ANA & $(-)$ & $\mathrm{Ca}$ & $8.4 \mathrm{mg} / \mathrm{dl}$ \\
\hline $\mathrm{RBC}$ & $422 \times 10^{4} / \mu 1$ & Anti-DNA Ab & $(-)$ & T-bil & $0.4 \mathrm{mg} / \mathrm{dl}$ \\
\hline $\mathrm{Hb}$ & $11.5 \mathrm{~g} / \mathrm{dl}$ & Anti-Jo-1 Ab & $(-)$ & AST & $17 \mathrm{IU} / l$ \\
\hline Hct & $34.8 \%$ & Anti-RNP Ab & $(-)$ & ALT & $9 \mathrm{IU} / l$ \\
\hline PLT & $39.9 \times 10^{4} / \mu \mathrm{l}$ & $\operatorname{Ig} \mathrm{A}$ & $293 \mathrm{mg} / \mathrm{dl}$ & LDH & $225 \mathrm{IU} / \mathrm{l}$ \\
\hline \multirow[t]{2}{*}{ ESR } & $46 \mathrm{~mm} / \mathrm{h}$ & IgG & $1,120 \mathrm{mg} / \mathrm{dl}$ & ALP & $257 \mathrm{IU} / l$ \\
\hline & & IgM & $208 \mathrm{mg} / \mathrm{dl}$ & $\gamma$-GTP & $60 \mathrm{IU} / l$ \\
\hline [Urinalysis] & & $\operatorname{IgD}$ & $2 \mathrm{mg} / \mathrm{dl}$ & AMY & $48 \mathrm{IU} / l$ \\
\hline Protein & $(2+)$ & $\mathrm{C}_{3}$ & $59 \mathrm{mg} / \mathrm{dl}$ & CPK & $189 \mathrm{IU} / \mathrm{l}$ \\
\hline Sugar & $(-)$ & $\mathrm{C}_{4}$ & $34 \mathrm{mg} / \mathrm{dl}$ & Ferritin & $105 \mathrm{ng} / \mathrm{ml}$ \\
\hline Blood & $(2+)$ & $\mathrm{CH}_{50}$ & $34 \mathrm{IU} / \mathrm{ml}$ & & \\
\hline \multirow{2}{*}{\multicolumn{2}{|c|}{ Bence-Jones protein }} & & & \multicolumn{2}{|c|}{ [Endocrinology] } \\
\hline & & \multicolumn{2}{|l|}{ [Biochemistry] } & TSH & $3.7 \mu \mathrm{IU} / \mathrm{ml}$ \\
\hline [Stool] & & $\mathrm{TP}$ & $6.5 \mathrm{~g} / \mathrm{dl}$ & $\mathrm{FT}_{3}$ & $1.40 \rho g / m l$ \\
\hline \multirow[t]{4}{*}{ Occult blood } & $(-)$ & Alb & $3.7 \mathrm{~g} / \mathrm{dl}$ & $\mathrm{FT}_{4}$ & $1.40 \mathrm{ng} / \mathrm{dl}$ \\
\hline & & Glu & $62 \mathrm{mg} / \mathrm{dl}$ & Thyrogl & $(-)$ \\
\hline & & BUN & $58 \mathrm{mg} / \mathrm{dl}$ & Anti TP & $(-)$ \\
\hline & & $\mathrm{Cr}$ & $4.7 \mathrm{mg} / \mathrm{dl}$ & & \\
\hline
\end{tabular}
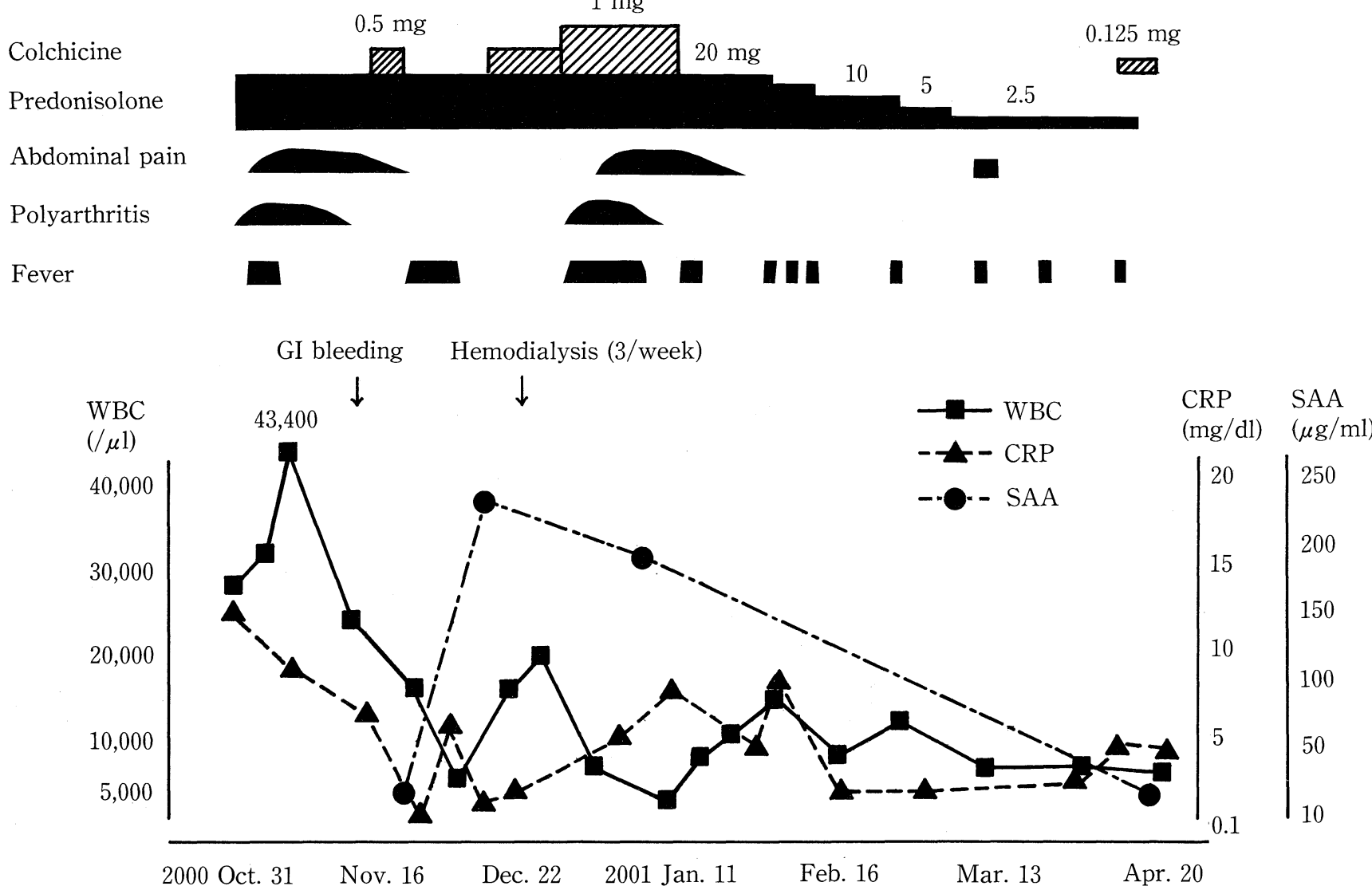

Figure 1. Clinical course. 
normalized. Thereafter, he had severe bleeding of the upper digestive tract, and the biopsies of the duodenum and colon showed AA amyloid deposition. Crohn's disease was denied by the finding of colon fiber. After treatment by IVH and a proton pomp inhibitor, the bleeding was improved.

The patient did not satisfy the diagnostic criteria of rheumatoid arthritis or other collagen diseases. We suspected FMF, because there was no evidence of any other disease and due to the clinical manifestations such as recurrent fever with peritonitis, arthritis and inflammatory changes, and the complication of secondary amyloidosis. However, no other family member had recurrent fever. The patient was given a $0.5 \mathrm{mg}$ of colchicine. After admission, renal insufficiency progressed gradually and he had congestive heart failure. He was transferred to our department on December 22, and he was placed on maintenance hemodialysis on the same day (Fig. 1). The patient had repeated febrile attacks once or twice a month lasting 6

\section{Ile Met Met Lys Glu}
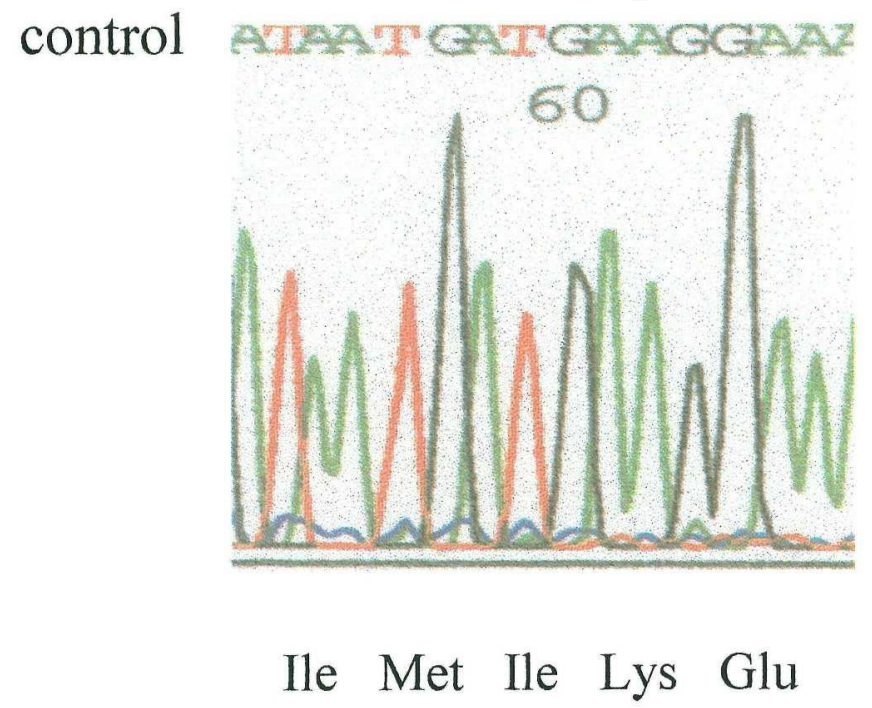

\section{patient}

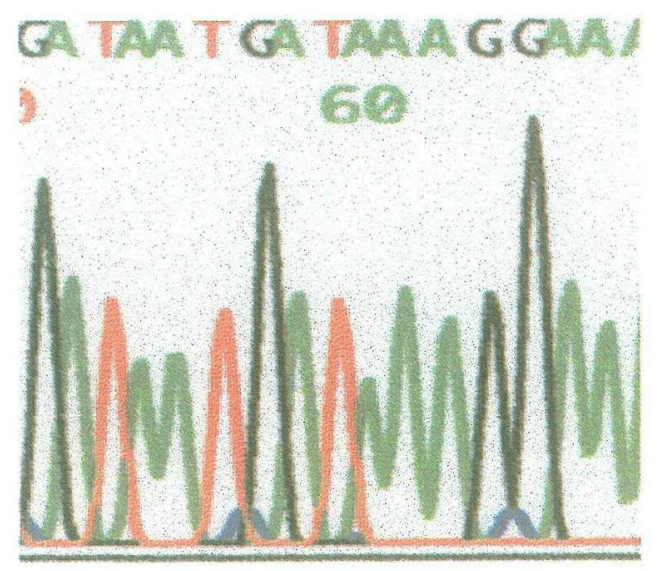

Figure 2. $M E F V$ gene analysis. hours to 1 day accompanied by inflammatory findings, abdominal pain and arthritis. Colchicine was increased to $1 \mathrm{mg}$ per day, but we had to stop due to the appearance of bone marrow suppression (Fig. 1). IL-1, TNF and dopamine $\beta$-hydroxylase were not increased in the febril phase. To make a definitive diagnosis of FMF, we performed gene analysis after obtaining the written informed consent from the patient. According to the phenol chloroform method, genomic DNA was extracted from peripheral leukocytes. We screened the exon 10 in MEFV gene because this region has more frequent mutations in FMF (1). Polymerase chain reaction (PCR) was performed including the lesion using the primer : forward primer ( $5^{\prime}$ GAGCCTGCAAGACATCCATA $3^{\prime}$ ) and reverse primer (5'TGACCACCCACTGGACAGAT3'). The PCR products were analyzed on a ABI 310 DNA sequencer in both directions.

The patient was homozygous for the M694I mutation which is a known $M E F V$ mutation $(\mathrm{G} \rightarrow \mathrm{A}$ transversion of nucleotide that results in substitution of isoleucine for methionine) (Fig. 2).

\section{Discussion}

Familial Mediterranean fever (FMF) is an autosomal recessive disease, characterized by recurrent attacks of fever and peritonitis, pleuritis, arthritis, or erysipelas-like skin disease. The symptoms are not apparent between attacks. The disease affects certain ethnic groups, mainly Sephardic Jews, Armenians, Turks, and Arabs. A typical attack consists of fever and serositis, lasting from one to four days. Between attacks, patients are free of symptoms. Until recently, a diagnosis of FMF was based on clinical manifestations, ethnicity, family history, and response to colchicine. In 1997, two independent consortia identified and isolated the gene responsible for FMF (MEFV) on the short arm of chromosome $16(2,3)$. Cloning of MEFV now allows a new and reliable diagnostic test for FMF. The gene responsible for FMF spans 10 exons, and encodes a 781 amino acid protein. The international FMF Consortium has named the protein encoded by $M E F V$ Pyrin, while the French FMF Consortium named it Marenostrin, the Greek name for the Mediterranean Sea. To date, 26 mutations have been found in $M E F V$ (4). Most mutations are missense mutations that result in the substitution of a single amino acid.

In Japan, FMF is a very rare disease. There are only 15 reported cases ( 2 cases with family history) since Hayashi et al reported the first case in $1976(5,6)$. One of the most significant complications of FMF is amyloidosis, usually affecting the kidneys, resulting in end-stage renal disease (ESRD). Amyloidosis may also affect the adrenal glands, gastrointestinal tract, spleen and liver. It less commonly, affects the lung, thyroid, heart, stomach, and testes $(7,8)$. The patient presented with secondary amyloidosis of kidneys, gastrointestinal tract, heart and perhaps thyroid. The amyloid protein is of the AA type, typical of secondary amyloidosis. Its prevalence differs among various ethnic groups and usually depends on whether or not the patient is treated with colchicine, which significantly decreases its incidence. Most patients who develop amyloidosis do so by the age of 40 years. Several studies comparing pheno- 
type manifestations and genotype analysis have disclosed that patients with FMF homozygous for the M694V mutation have a more severe disease manifestation by early onset, more frequent attacks, joint disease, and require higher doses of colchicines (9-11). Moreover, such patients are prone to develop amyloidosis $(11,12)$. The prevalence of amyloidosis among the FMF population has been thought to be independent of the frequency, duration, and intensity of flares (8). Shohat et al (10) and Livneh et al (12) showed that M694V mutation significantly is correlated with the presence of amyloidosis compared with other mutations. Ben-Chetrit and Backenroth (13) showed that 23 patients with ESRD induced by amyloidosis were homozygous for the M694V and M691I mutations and concluded that amyloidosis is highly associated with the 694 substitution in the MEFV gene causing FMF. The present patient was homozygous for the M694I mutation and it may have a relation to amyloidosis. No case with amylidosis has been reported in Japan.

It is known that neutrophils accumulate in areas of inflammation during FMF attacks, but the molecular mechanism by which this happens has remained obscure. The secretion of mediators of inflammation such as interleukin- 1 and the tumor necrosis factor (TNF) has been reported to increase during acute attacks, whereas, interferon activity is decreased $(14,15)$. Serosal fluids, especially from the peritoneal cavity or from the synovia, were reported to have reduced activity of the C5a inhibitor (16), and, since C5a is a highly potent chemoattractant of granulocytes, it has been suggested that a lack of its inhibitor might account for the acute attacks of inflammation. Others have claimed that the disorder in FMF is related to catecholamine metabolism (17). Long-term colchicine treatment has been used for FMF (18). Colchicine inhibits the increased chemotactic activity occuring during FMF attacks and is concentrated mainly in neutrophils (19). Colchicine is of paramount importance in preventing FMF amyloidosis and it may also arrest the progression of amyloidosis in those who already have it (20). We tried to treat the patient with colchicine but had to decrease the dose due to bone marrow suppression.

\section{Conclusion}

We reported the 16th case of FMF in Japan, and diagnosed the existence of the FMF gene. Our genotype analysis disclosed that the patient was homozygous for the M694I mutation which is thought to be associated with complications of amyloidosis. The patient was placed on maintenance hemodialysis due to renal amyloidosis.

\section{References}

1) Samuels J, Aksentijevich I, Torosyan Y, et al. Reviews in Molecular Medicine; Familial Mediterranean Fever at the Millennium Clinical Spectrum, Ancient Mutations, and a Survey of 100 American Referrals to the National Institutes of Health. Medicine (Baltimore) 77: 268-297, 1998.

2) The International FMF Consortium. Ancient missense mutations in a new member of the RoRet gene family are likely to cause familial Mediterranean fever. Cell 90: 797-807, 1997.

3) The French FMF Consortium. A candidate gene for familial Mediterranean fever. Nat Genet 17: 25-31, 1997.

4) Pras M. Review; Amyloidosis of Familial Mediterranean Fever and the MEFV gene. Amyloid. Int J Exp Clin Invest 7: 289-293, 2000

5) Hayashi A, Suzuki T, Shimizu A, Yamamura Y. Periodic fever suppressed by reserpine. Lancet 1: 592, 1976 (letter).

6) Doi S, Murai K, Okayama A, et al. Familial Mediterranean fever with erythema nodosam in an adult. Jpn J of Rheumatology 6: 147-154, 1996.

7) Ben-Chetrit E, Levy M. Familial Mediterranean fever. Lancet 351: 659664, 1998.

8) Hellar H, Sohar E, Gafni J, Heller J. Amyloidosis in familial Mediterranean fever. An independent genetically deternmined character. Arch Intern Med 107: 539-550, 1961.

9) Dewalle M, Domingo C, Rozenbaum M, et al. Phenotype-genotype correlation in Jewish patients suffering from familial Mediterranean fever. Eur J Hum Genet 6: 95-97, 1998.

10) Shohat M, Magal N, Shohat T, et al. Phenotype-genotype correlation in familial Mediterranean fever: evidence for an association between Met694Val and amyloidosis. Eur J Hum Genet 7: 287-292, 1999.

11) Cazeneuve C, Sarkisian T, Pecheux $\mathrm{C}$, et al. MEFV-gene analysis in $\mathrm{Ar}-$ menian patients with familial Mediterranean fever: diagnostic value and unfavorable renal prognosis of the M694V homozygous genotype-genetic and therapeutic implications. Am J Hum Genet 65: 88-97, 1999.

12) Livneh A, Langevitz $P$, Shinar $Y$, et al. MEFV mutation analysis in patients suffering from amyloidosis of familial Mediterranean fever. Amyloid 6: 1-6, 1999 .

13) Ben-Chetrit E, Backenroth R. Amyloidosis induced, end stage renal disease in patients with familial Mediterranean fever is highly associated with point mutations in the MEFV gene. Ann Rheum Dis 60: 146-149, 2001.

14) Ozyilkan E, Simsek $H$, Telatar $H$. Tumor necrosis factor in familial Mediterranean fever. Am J Med 92: 579-580, 1992 (letter).

15) Rozenbaum M, Katz R, Rozner I, Pollack S. Decreased interleukin 1 activity released from circulating monocytes of patients with familial Mediterranean fever during in vitro stimulation by lipopolysaccharide. $\mathrm{J}$ Rheumatol 19: 416-418, 1992.

16) Matzner Y, Ayesh SK, Hochner-Celniker D, Ackerman Z, Ferne M. Proposed mechanism of the inflammatory attacks in familial Mediterranean fever. Arch Intern Med 150: 1289-1291, 1990.

17) Barakat MH, EI-Khawad AO, Gumaa KA, El-Sobki NI, Fenech FF. Metaraminol provocative test: a specific diagnostic test for familial Mediterranean fever. Lancet 1: 656-657, 1984.

18) Goldfinger SE. Colchicine for familial Mediterranean fever (Letter). $N$ Engl J Med 287: 1302, 1972.

19) Chapey ON, Neil E, Wautier JL, et al. Colchicine deposition in human leukocytes after single and multiple oral administration. Clin Pharmacol Ther 54: 360-367, 1993.

20) Zemer D, Livneh A, Langevitz P. Reversal of nephritic syndrome by colchicine in amyloidosis of familial Mediterranean fever. Ann Intern Med 116: 426, 1992 (letter). 